\title{
BLASTOMICOSE SUL-AMERICANA
}

José Antônio Grandini Kulczynski, Cirurgião-Dentista Interno do Departamento de Cirurgia e Ortopedia

\section{SINOPSE}

Observação de 11 casos e realizasio de um retrospecto na literatura correspondente. Uniformização das sbserrações e relatos, incluindo ocorrència, fonte de infecção, cultura do fungo, técnicas de laboratório, aspectos histológico, radiológico e clínico e tratamento para a moléstia.

\section{INTRODUÇO}

Recebendo denominações as mais diversas, de acôrdo com as características clínicas observadas, com as interpretações pessoais e de acôrdo com a vontade de muitos observadores, a Blastomicose sul-americana foi aos poucos, acumulando nomes que se fôssem aqui catalogados, tornariam ainda mais exaustiva a leitura dêste trabalho.

Alguns dos nomes mais conhecidos são, Moléstia de Lutz, Blastomicose sul-americana, Paracoccidiocidose. Mesmo naqueles em que se notam variantes, em suas manifestações, lo- calizações ou de qualquer outra ordem, nos parece mais acertada a denominação de Blastomicose sul-americana. Sendo notadas características extraordinárias estas poderiam ser citadas como apêndice, que seria colocado entre parêntesis, ex.: Blastomicose sul-americana - (tipo Alto Xingú).

Procuramos no presente trabalho agrupar opiniões que se somam e outras que se colidem, quase sempre devido a diferentes observações, o que é bastante compreensivel uma vez que são feitas em organismos vivos que se comportam de diferentes maneiras, que vivem sob diversos meios ambientais e que principalmente, foram estudados por diferentes observadores usando diferentes métodos.

Além da revisão bibliográfica, revisamos todos os casos observados na Cadeira de Patologia da Faculade de Odontologia da UFRGS e observamos alguns casos nesta mesma $\mathrm{Fa}$ culdade e nas enfermarias de Dermatologia da Santa Casa de Misericórdia de Pôrto Alegre. 


\section{DEFINIQ̃̃o}

Segundo Connant ${ }^{25}$, Blastomicose sul-americana é uma doença crônica, granulomatosa, da pele, membranas mucosas, nódulos linfáticos e órgãos internos, causada pelo Blastomyces brasiliensis.

\section{OCORRÊNCIA}

A maioriá dos casos constatados é entre os homens; Almeida ${ }^{3}$ examinando 550 casos, encontrou 496 homens e 54 mulheres afetadas, na proporção de 9,5 para 1. Dos 18 casos observados na Faculdade de Odontologia da UFRGS, apenas 1 foi $\mathrm{em}$ pessoa do sexo feminino. De 45 casos examinados na Santa Casa de Misericórdia de São Paulo, entre 1939 e 1944 foram constatados que $95 \%$ dos casos eram em homens e apenas $5 \%$ em mulheres ${ }^{2}$. Assim também outros observadores constataram predominância de ocorrência no sexo masculino, sendo que esta mais se acentua quanto maior fôr o número de casos estudados.

Quanto à idade, constata-se que a faixa de maior incidência está compreendida entre 20 e 40 anos de ida$\mathrm{de}^{2}$.

A grande maioria dos pacientes observados ocupam-se de afazeres manuais, principalmente no campo.

A higiente da maioria dos atacados pela enfermidade era precária, a alimentação deficiente. Organismos depauperados e sujeira, compõem um ótimo «meio de cultura» para o fungo.

São Paulo, Minas Gerais, Rio de Janeiro são as áreas onde maior número de casos foram encontrados no
Brasil, sendo que Rio Grande do Sul, Amazonas, Santa Catarina e de resto em todo o território nacional encontrou-se casos de Blastomicose sulamericana. Na Argentina, Uruguai, Venezuela, Paraguai, Bolívia, Perú e Costa Rica ${ }^{25}$ foram encontrados casos de Blastomicose sul-americana. Edward ${ }^{28}$, narra um caso encontrado nos EEUU. em Honduras e no México, há registro de um caso em cada país. Bastante curioso é o caso encontrado na Bulgaria 7 , pois o paciente apresentou-se com o mal, sòmente 30 anos após ter regressado do Brasil. O caso ocorrido na Suiça, é de um homem que trabalhava com madeiras importadas do Brasil.

Fava Netto ${ }^{29}$, encontrou em suas observações 4 casos de ocorrência familiar de Blasomicose, 2 casos entre pai e filho e 2 casos entre irmãos, entretanto isto parece não ter significado maior. $\mathrm{E}$ uma percentagem insignificante dentro do total de casos estudados, e para nós apenas confirma a idéia de que as condições de vida deficientes são bastante favoráveis à contaminação pelo fungo.

Em outros autores nada encontramos que nos leve a acreditar que exista a possibilidade de ordem hereditária ou de contágio direto.

\section{FONTE DE INFECC}

Todos os autores afirmam ser desconhecida a fonte de infecção, entretanto, todos concordam que possìvelmente a infecção se dá através de exógenos existentes na natureza9,25. A maioria das pessoas que se apresentavam com a enfermidade estiveram em contato direto com a natu- 
reza, principalmente na vida rural, trabalhando com madeiras, levando gravetos e fôlhas sêcas à bôca, etc. A grande maioria vive em condições precárias de higiente, e certamente aí mais se acentua a presença do organismo da infecção.

Tendo sido constatada a infecção imediatamente após extrações dentárias, e devido ao fato de a maioria das lesões incidirem sôbre a mucosa oral, acredita-se ser esta a principal porta d e entrada da infecção $2,9,11,16,22,25,27,33,37,38$. Alguns $^{4}, 12,35$ acreditam que por inhalação é possível a infecção, baseados no fato de terem encontrado como suposta infecção primária o pulmão. Acreditam êstes que as demais localizações seriam meramente secundárias e o fungo transportado pelo sangue a êstes locais. Boydic, tendo estudado vários casos, presume ser a pele a via de entrada do Blastomyces brasiliensis e Bogliolo, segundo Shafer 42 afirma que através dos tecidos periodontais pode se dar a penetração no organismo e conseqüentemente alcançar os gânglios linfáticos regionais com produção de uma severa linfadenopatia.

\section{ASPECTO CLÍNICO}

O simples exame clínico da lesão é ineficaz para um diagnóstico seguro da enfermidade. Seu aspecto varia muito, de acôrdo com sua localização, tempo de infecção: resistência orgânica. O aumento dos nódulos linfáticos é talvez o aspecto clínico mais característico ${ }^{25}$.

Vários autores, principalmente Almeida $^{3}$ classificam a infecção em: forma cutânea; forma linfagítica; forma visceral e forma mista.

a) Forma cutânea - sendo que a infecção primária é encontrada principalmente na superfície mucosa da língua, bochecha, gengiva, palato, lábio e nariz. Áreas amarelas ou avermelhadas são encontradas na superfície e os bordos da lesão são rasos. A expansão da infecção pode levar até a destruição dos tecidos subjacentes, pois quanto mais se expande, mais se aprofunda. Além de dolorosas, estas lesões podem causar dificuldades de deglutição e fonação. A morte por caquexia é o resultado dêste quadro 25 .

A propagação da infecção vai atingir os nódulos linfáticos que tornamse fàcilmente palpáveis. Muitas vêzes, não houve lesão na zona de entrada (bôca) e sòmente nota-se uma protuberância linfática que pode ser o único sintoma clínico por muito tempo até que ocorre a formação de uma fístula através da pele para a drenagem; esta é a

b) Forma linfangítica.

c) Forma visceral - Conam ${ }^{25}$ afirma que a porta de entrada para êste tipo de infecção é o aparelho gastro-intestinal, devido ao fato de as maiores lesões se encontrarem nas regiões Cecal e Apendiceal. Distúrbios gastro-intestinais, vômitos, anorrexia, febre moderada, são os sintomas desta forma. Os pulmões estão envolvidos em $80 \%$ dos pacientes. O fungo invade os pulmões secundàriamente através da via hematógena. Fígado, baço e outros orgãos se dilatam.

Apesar desta valiosa opinião de Conan, acreditamos que o mecanis- 
mo para esta instalação do fungo nas vísceras é o mesmo que ocorre na forma linfangítica, ou seja, por possível resistência local, os sintomas de ordem oral, não se manifestam clìnicamente, indo então a enfermidade manifestar-se sòmente em sua localização secundária ao nível das vísceras.

d) Na Forma mista, encontramos várias localizações' e o quadro clínico é variado. Entretanto, todo o exame clínico é precário, por exemplo, fàcilmente podem as lesões bucais serem confundidas com lesões tuberculosas, o mesmo ocorrendo na infecção pulmonar pela Blastomyces brasiliensis. Daí a necessidade $\begin{array}{ll}38 & 27\end{array}$ e importância do Exame anátomo-patológico dos tecidos infectados.

\section{ASPECTO DO FUNGO ì OBSER- VAC̣̃̃O E TÉCNICAS}

Têm sido descritos três tipos de fungos como causadores da enfermidade porém alguns estudiosos crêem que as diferenças entre êles são de pouca monta e considera-se uma só variedade de fungo como agente etiológico 25 .

Poderá o agente ser encontrado nos tecidos, através de diversas técnicas quer por observação direta ao microspópio, quer por culturas.

O exame microscópico direto, é realizado colocando-se uma pequena quantidade de pús, sôbre uma laminula; se o material ficar muito escuro para a observação, pode-se usar hidróxido de potássio a 10-44\% com a finalidade de clareá-lo. Não faz-se coloração.

Sob a forma de culturas, o fungo é observado após «culturas» a $37^{\circ} \mathrm{C}$, com o desenvolvimento parecido com leveduras e à temperatura ambiente com desenvolvimento parecido ao bolor.

Para conseguir-se a cultura, colhese o material por raspagens ou biópsias, principalmente através do pús é que se conseguem melhores resultados. No caso de ser cultivado à temperatura ambiente, o meio de cultura usado é o de placas de ágar-glicose de Sabouraud e em caso de fazer-se à $37^{\circ} \mathrm{C}$, ágar-sangue. Tanto num como noutro meio de cultura, o resultado é demorado, podendo ultrapassar 30 dias. Nas culturas podemos diferenciar o Blastomyces brasiliensis do Blastomyces dermatitidis, pois enquanto o primeiro pussui crescimento reduzido, o segundo cresce de maneira vigorosa $9,25$.

Inoculação em testículo de cobaio ${ }^{6}$, é um processo a que podemos recorrer para obtermos material suficiente para uma boa observação, pois no tecido testicular o fungo é fàcilmente «cultivado».

Ao microscópio, o Blastomyces brasiliensis apresenta-se com o aspecto espumoso, com dupla membrana e brotamento simples e múltiplo.

Para observação direta fixa-se a peça por biópsia em formol a $10 \%$, em líquido de Carnoy e finalmente em álcool absoluto 33. Para impregnação argentica, podem-se obter os fragmentos através do método de inclusão em parafina, em cortes de $3 \mathrm{e}$ 5 micra ou pelo método da congelação em cortes de 10 a 15 micra. Além das impregnações argênticas podem ser usadas técnicas de coloração pelo P. A. S. e Sudam IV. 
Ramos 40 salienta que pelo método do contraste de fase nos preparados histopatológicos, corados ou não, $\checkmark$ fungo se mostra com mais ou mezos intenso brilho luminoso.

Parace ser o método Rio Hortega de impregnação de prata, a forma mais aconselhada para a posterior observação.

Pela coloração Hematoxilina-eosina. observaremos a cápsula do fungo de côr róseo-avermelhada, enquanto que o corpo celular apresenta-se róseo-azulado ou roxoazulado, ou ainda, com tendência para uma côr avermelhada.

Pela coloração pelo carbonato de prata, o microrganismo apresentarse-á em negro. Pelo Sudan IV, a côr do fungo é avermelhada, com variantes de intensidade no citoplasma, e a cápsula embora nítida, não apresenta-se corada.

Existem várias variantes de técnicas, sendo que cada uma delas pode salientar algum caráter específico, como forma, granulações, membrana.

Sòmente a presença do fungo nos tecidos nos dá a certeza do diagnóstico certo $^{38}$.

\section{ASPECTO HISTOLOGICO}

Tendo o material da lesão sido obtido através de biópsia, vamos incluí-lo em parafina e seguindo-se o roteiro usual, obter cortes de 3 a 5 micra. Após o ritual da coloração e fixação, vamos levar as lâminas ao microscópio e observaremos os seguinte: reação granulomatosa das células, caracterizada pelo grande número de células gigantes, e dentro destas ou pelo menos em algumas, podemos encontrar o fungo, bastante caracterizado. Observa-se claramente uma hiperplasia do tecido epitelial, o que pode levar o observador desavisado a confundir com carcinoma dada a grande semelhança. A presença de células gigantes pode levar à conclusão errônea, dada a semelhança com a tuberculose, então a presença de fungo no interior destas células é que nos dá condições de diagnóstico certo.

Micro-abcessos com infiltração da polimorfonucleares e lesões focais necróticas circundadas por células gigantes, macrófagos, linfócitos e tecido fibroso podem ser observados em áreas diversas.

Necessàriamente, vai influir no aspecto histológico, a zona do organismo que está infectada. Os métodos de coloração já foram relatados anteriormente, porém deve-se salientar, ainda, a Reação de Fixação do Complemento. Cisalpino ${ }^{24}$ e outros, usando antígeno metílico obtiveram 34 casos postivos de fixação do complemento em 35 casos comprovados.

\section{EXAME RADIOGRÁFICO}

O exame radiográfico do tórax, bem como do abdomen, quando existem sintomas que despertem a atenção, são de grande valia para poder-se conhecer a extensão da lesão. Entretanto, não pode servir de base quando não dispomos de outros exames. Apesar do auxílio dêste meio de pesquisa, sòmente o achado do fungo, voltamos a afirmar, poderá nos dar um diagnóstico seguro. Lesões pulmonares, principalmente nas bases, podem ser devidas e confundidas com tuberculose. 


\section{TRATAMENTO}

As primeiras tentativas de tratamento da enfermidade basearam-se no uso de iodetos. $\mathrm{O}$ iodeto de potássio foi o mais empregado e administrado por via oral. «Penicilina, estreptomicina e as sulfonamidas são valiosas quando existem microrganismos invasorés secundários sensíveis》12.

Segundo Tiecke ${ }^{45}$ se têm usado com êxito os derivados do estilbamidine e 2-hidroxistilbamidine. 0 mesmo autor refere-se ao uso da radioterapia, afirmam que a blastomicose responde ao citado tratamento, o que nos parece de todo desaconselhável, pelos efeitos prejudiciais do mesmo.

Já Bernier ${ }^{12}$ afirma que se desconhece tratamento eficaz e que são valiosas medidas de sustento geral e é útil o iodeto de potássio. Segundo o mesmo autor, a anfotericina-B tem sido usada com êxito alentador, e a mesma opinião encontramos em oùtros autores como Jawetz.

Nos pacientes internados nas enfermarias de Dermatologia da Santa Casa de Misericórdia de Pôrto Alegre, sob direção do Dr. Carlos Bopp, tem sido usada com muito sucesso a piretoterapia associada a sulfamidoterapia. A piretoterapia consiste na aplicação de T. A. B. o que faz com que eleve-se a temperatura do paciente a uma média de $39-40^{\circ} \mathrm{C}$ e com êste meio o próprio organismo combate o fungo.

Tivemos oportunidade de observar um caso de melhora excepcionalmente rápida em paciente que apresentava-se com características as mais violentas da moléstia. $O$ paciente (ca- so XI) ficou com as feições deformadas, apresentando o característico «lábio de tapir». Em 15 dias de tratamento, $a{ }_{\star}$ regressão, baseada apenas na sintomatologia clínica, pode dizerse total.

A excisão das lesões cutâneas, segundo Bernier12 é totalmente contraindicada. Entretanto,, Tiecke ${ }^{45}$ recomenda a intervenção cirúrgica cuidadosa para estabelecer drenagem.

\section{CASOS E ESTATISTICA}

Caso I - H. M. M. - masculino, branco, brasileiro, casado, 44 anos de idade, foguista, Sapucaia do sul.

o paciente apresentou-se em maio de 1964, relatando um passado de 10 anos com sintomas semelhantes ao da queixa atual. Há 1 ano após extração dentária, por estarem os dentes abalados, sentiu intensa «ardência na mucosa» e começou a disseminação do mal. Antes disso, não precisando a data, extraiu por si próprio, com instrumentos diversos, alguns dentes, também abalados. Costumava espalitar os dentes com fragmentos de madeira. As lesões por ocasião do exame localizavam-se na gengiva o palato. Por observação de tecidos ao microscópio, foi constatada a presenca de Blastomyces brasilienses.

Caso II - M. P. - masculino, branco, brasileiro, casado, 37 anos de idade, comerciante, Blumenau.

Apresentou-se em outubro de 1964, por indicação de um dentista, por ter o lábio inferior, lado direito já há algum tempo aumentado de volume. Em setembro de 1963 , fôra operado de uma úlcera no lábio, tendo 
2. exame anatomo-patológico dado o - esultado de inflamação crônica com 匹lceração, estágio pré-carcinomatoso. Hả mais ou menos trệs meses houve Iôro aumento de volume razão por que foi feita outra biópsia. A gengira correspondente aos dentes anteriores $\mathrm{e}$ inferiores do lado direito se apresenta ulcerada. Biópsia-Blastomicose.

Caso III - I. N. - masculino, branco. brasileiro, casado, 34 anos de idade, pedreiro, São Sebastião do Caí.

Apresentou-se na Cadeira de Patologia da Fac. de Odontologia da LFRGS, em novembro de 1964, por indicação do dentista. Há seis meses já sentia dificuldade em realizar movimentos normais de A. T. M. Relata odontalgia, ardor com uso de fumo € bebidas alcoólicas. Extraiu $\mid 4.5$, harendo cicratização imperfeita. Presença de granulações no palato duro e mole, zona com coloração vermetha intensa ao nível dos dentes extraidos. Por ocasião de sua apresentação, já estava sob terapêutica à base de sulfadiazina, 6 comprimidos ao dia, há mais ou menos $21 / 2$ meses. Relata grande melhora com o tratamento. A biópsia revelou Blastomicose sul-americana.

Caso IV - L. F. D. - masculino, branco, brasileiro, casado, 58 anos, agricultor, Canoas.

Em janeiro de 1966, por recomendaçãc de um dermatologista, procurou o patologista. Há três meses sente dificuldade de deglutição. Apresenta desde então uma placa erosada no cavum. Esta placa, extensa erosada de forma arredondada, medindo cerca de $4 \mathrm{~cm}$., localiza-se no palato mole $\mathrm{D}$, limitando o palato duro e linha gengival. Seu fundo é levemente vegetante, pontilhado de um amarelo purulento e também hemorrágico. Exames ao nicroscópio, conformaram a suposição de Blastomicose sulamericana.

Caso V - A. C. - masculino, branco, brasileiro, casado, 50 anos, agricultor, Panambi.

Apresentou-se na Santa Casa de Misericórdia de Pôrto Alegre, em novembro de 1967, e de lá foi remetido ao patologista. Apresentava no lábio superior, ulceração arredondada, endurecida, rosa claro, aspecto irregular com rebordos cornificados. Relatou que no ano anterior lesões semelhantes regrediram com tratamento à base de sulfas, com exceção da lesões ao nivel gengival. Exames patológicos positivaram a suspeita de Blastomicose sul-americana.

Caso VI - G. F. - feminina, branca, brasileira, solteira, 25 anos, afazeres domésticos, R. G. Sul

Remetida por um cirurgião, parte do tecido oral afetada que foi identificado como lesão por Blastomyces brasiliensis.

A lesão apresentava-se generalizada por tôda a cavidade oral, há uns seis meses. A biópsia foi realizada na região interna do lábio inferior.

Caso VII - V.I. - masculino, branco, brasileiro, casado. 38 anos, agricultor, Cachoeira do Sul.

Apresentou-se na Santa Casa de Misericórdia de Pôrto Alegre, por apresentar lesão na bôca que difi- 
cultava sobremaneira a deglutição e fonação.

Há 8 anos teve uma lesão na bôca, mais precisamente no palato duro, vesícula que após, rompeu alastrando-se por tôda a bôca. Nesta ocasião extraiu todos os dentes. Há seis anos fêz tratamento por $2 \quad 1 / 2$ meses com sălfonamidas. Há 5 anos, reicidiva, atingindo as gengivas e há 2 anos, afonia progressiva. Emagreceu mais ou menos 20 quilos. Intensa sialorréia. «Pontadas» no peito quando se movimenta. Má nutrição. Pele sêca e sem elasticidade, mas de côr normal. Lesões ulceradas atingindo todo o palato, destruídas partes da orofaringe, entre outras a úvula e as amígdalas. Lesões hiperemiadas com pontos esbranquiçados. Superfície irregular.

Gânglios - cervicais, sub-maxilares impalpáveis. Inguinais - palpáveis, duros e dolorosos, fixos em ambos os lados.

Condições de vida - casa de madeira, alimentação boa, higiene precária, fuma cigarros de papel, antes Iumava palheiro.

Respiração abdominal - murmúrio vesicular diminuído nas bases.

Tratamento - Sulfametoxipiridazina - dose de ataque, $500 \mathrm{mg} / \mathrm{dia}$ durante 15 a 20 dias; dose de manutenção, $250 \mathrm{mg} / \mathrm{dia}$.

Caso VIII - A.M. - masculino, branco, brasileiro, casado, 37 anos de idade, agricultor, Campoerô (Santa Catarina).

Há 7 meses, na região jugal direita, apareceram lesões ulceradas, pràticamente assintomáticas. Sentia dor ao deglutir e «dor de dente». Sia- lorréia abundante. Tosse sêca há 3 meses. Após o início da moléstia, foi paciente de 4 extrações dentárias.

Condições de vida - habita casa de madeira, toma água de vertente, usa Iatrina, má nutrição e fuma desde os 18 anos, ora cigarro de papel, ora palheiro.

Pele normal, adenopatia sub-mandibular em ambos os lados. Rx no tórax apresentou lesôes extensas mais ou menos simétricas em ambos os pulmões e compreendendo consolidações, pequenas cavidades e fibrose. Algumas das cavidades de aspecto cístico (5 $\mathrm{cm}$ de diâmetro). Os exames laboratoriais e microscópicos, dirigidos inicialmente para o bacilo de Koch, negativo. Após, dirigiram-se para o Blastomyces brasiliensis positivo.

Tratamento - dose de ataque com lentosulfina e dose de manutenção com o mesmo medicamento. Foram administradas doses de proteinas, como suplemento da alimentação.

Caso IX - A.R. - masculino, branco, brasileiro, casado, 42 anos, agricultor - RGS.

Apresentou-se com lesões erosadas, moriformes, abrangendo grande área da mucosa labial, bucal e língua, com eritema e edema perioral.

Pelo Rx, constatou-se cavidades de diferentes dimensões nos pulmões, algumas anfractuosas, ocupando principalmente os segmentos ápico-posterior superior e basais posteriores de ambos os pulmões. Presença de nódulos e estrias fibrosas e consolidações discretas. Pelas características das lesões, associadas ao quadro clínico, sugere Blastomicose sul-ame- 
ricana. Pelo exame microscópico dos tecidos, confirmação.

Tratamento - $\mathrm{TAB}-\mathrm{T}$ aplicacões com intervalos de 5 dias entre cada, sulfas em dose de ataque e manutenção. Bochechos com Bórax e elixir ferrugoso.

Caso X - B.K. - masculino, branco, brasileiro, casado, 47 anos, agricultor, Venâncio Aires.

Em março de 1968 apresentou-se com lesões ulceradas na mucosa oral. Após avulsão dentária, realizada 1 ano atrás, também ocorreu lesão ulcerada na mucosa oral, pontilhada de aspecto arenoso. O paciente é surdo-mudo, apresentando bom estado de nutrição.

Tórax normal, pulmões limpos e abdomem normal. A pele sêca, elástica.

Condições de vida - mora em casa de madeira, com higiene deficiente e alimentação boa. Fuma cigarros de papel e palheiros.

Tratamento - após 50 dias de sulfamidoterapia, apresenta uma cura clínica das lesões orais.

Caso XI - A.B.M. - masculino, branco, brasileiro, casado, 49 anos de idade, soldador, Caràzinho.

Há 6 meses foi ao dentista porque sentia um «carôço» sub-maxilar. Fêz extração de 2 molares inferiores do lado direito. Algum tempo depois, surgiu intensa «inflamação» nos lábios e bochechas, além do palato. Assintomáticos. Não teve sialorréia. Não sente nada de anormal em seu estado geral. Apresenta-se com edema e eritema no lábio superior. Extensa lesão ulcerada, de fundo granuloso, com pontilhado hemorrágico, difuso, parcialmente recoberta com exudato amarelado. A lesão abrange, mucosa labial superior, gengiva superior esquerda e palato mole. Gânglios submaxilares, duros, maiores à esquerda, inguinais duros, indolores.

Ao $\mathrm{Rx}$ - fibrose bilateral - nódulos e áreas de enfizema localizado.

Condições de vida - habita em casa de madeira e trabalha em oficina de «chão batido», água de poço e WC fora de casa (latrina). Tem o hábito de usar paus de fósforo para espalitar os dentes e fuma uma média de 20 cigarros por dia. Alimentação boa.

Tratamento - TAB de 5 em 5 dias, três aplicações.

Leutosulfina - 2 comprimidos ao dia/3 dias e 1 ao dia a seguir.

Êste paciente apresentou recuperação rápida e espantosa após 15 dias de tratamento.

Nos 11 casos acima relacionados, constamos que:

a) todos os pacientes com Blastomicose sul-americana, dedicam-se a afazeres manuais, sendo que a maioria tem ainda o costume ou de fumar cigarros de palha ou levar gravetos ou pedaços de madeira à bôca;

b) de todos os casos relacionados, apenas um é em pessoa do sexo feminino;

c) habitação - todos moram em casa de madeira, com higiene defi- 
ciente, nenhum paciente usa água encanada e tratada;

d) apenas nos dois últimos casos, verificou-se uma boa alimentação, sendo que nos demais encontrou-se sinais de depauperação orgânica;

e) a média de idade dos individuos afetados, está entre 35 e 45 anos;

f) todos os pacientes são brasileiros e de côr brańca;

g) de todos os casos, apenas 2 apresentavam complicações pulmonares (casos VIII e IX);

h) enquanto dois pacientes não relatam passado patológico localizado nas áreas hoje afetadas, 4 pacientes mencionam lesão oral anterior, e 6 cntre os 11, antes ou no início das manifestações patológicas fizeram extrações dentárias.

\section{DISCUSSÃO}

Apesar da diversificação de denominações e pequenas discrepâncias, só existe um microorganismo responsável pela moléstia. Havendo uma infecção secundária por outros microorganismos, êstes poderão alterar o quadro clínico. Pelos casos observados podemos afirmar que a via principal de acesso e instalação da Blastomicose sul-americana é de fato a cavidade oral, devendo-se o fato de outras localizações, conforme relato de autores já mencionados, a maior ou menor resistência destas partes do organismo e lesões anteriores, como nos parece ser o caso relatado por Londero \& Fabrício (36) onde a localização do Blastomyces brasiliensis é em órgão genital.

Casos relatados, de estrangeiros que muitos anos após terem regressado do Brasil, apresentaram-se com Blastomicose sul-americana, nos fortalecem,a opinião de que o fator de resistência local, no caso, resistência nos tecidos orais, pode determinar um estado sub-clínico e posterior manifestação de grande intensidade a distância da porta de entrada do fungo.

$O$ fato de 6 pacientes em 11 relatarem extrações dentárias como motivo de exarcebação, bem como dentes abalados, além de todos os casos apresentarem lesões orais, nos chama atenção para a responsabilidade do cirurgião-dentista quanto à identificação da doença e tratamento adequado.

No que se refere ao tratamento da doença, embora não haja uma conduta uniforme e comprovadamente eficaz, nos parece a terapêutica utilizada na Enfermaria de Dermatologia da Santa Casa de Misericórdia, sob a direção do Prof. Dr. Carlos Bopp, a mais indicada, baseados nos casos observados. Associação de antibióticos, cremos estar indicada sòmente quando comprovadamente houver infecção secundária.

A idéia de relacionar a doença com hereditariedade, nos parece desprovida de sentido, uma vez que de todos os casos mencionados por autores, apenas 4 casos foram relatados, o que nos dá uma percentagem desprezivel de ocorrência familiar.

A média de idade dos 11 casos observados por nós, é de 35 a 45 anos, o que vem de encontro com a opinião de vários autores, principalmente Aleixo, de que a faixa de idade em que há maior incidência é a de 20 a 40 anos. 
O fato de um maior número de 亡omens ser afetado, não nos parece ser determinado por um fator cromossômico, senão por estarem os homens mais ligados a afazeres que os colocam em contato mais direto com a natureza, e a costumes e vícios e também a serem mais descuidados no que se refere à higiene pessoal, que as mulheres, tudo isto lògicamente relacionado com o meio social em que vive a maioria dos afetados.

\section{SYNOPSIS}

The author, beyond the observa. tion of 11 cases reported in this work, have realized a retrospection in the concerning literature. They tryed to uniforming sparse observations and relates, including in this work occurrence, infection source, morel culture laboratorial technics, histologic, radiologic and clinical aspects, and treatment for the infirmity.

\section{REFERENCIAS BIBLIOGRÁFICAS}

1. AJELLO, Libero. Laboratory manual for medical mycology. Atlanta, U. S. Dept. of Health, Education and Walfare, 1963. p. 11-14.

2. ALEIXO, J. Estudo clínico - terapêutico da blastomicose brasileira. In: 11 reunião anual dos dermat-sifilógrafos brasileiros. Minas Gerais, Imprensa Oficial, 1948, p. 177-83.

3. Almeida, F. P. et alii. Revista Brasileira de Medicina, Rio de Janeiro, $3: 91-4,1946$.

4. ANDERSON, W. Synopsis of pathology. 3.ed. S. Louis, Mosby, 1960. p. 167: 731 .

5. ANDERSON, W. Tratado de patologia. 3.ed. Buenos Aires, Intermédica, 1961. p. 407.

6 APRILE, Humberto et alii. Terapeutica clinica, enfermedades da boca, esofago y estomago. Buenos Aires, El Ateneo, 1958, p. 17.

7. BALABANOV, K. et alii. South American blastomycosis in a Bulgarian laborer returning after 30 years in Brazil. Mycopathology, Den Haag, 24:265-70, 21. Dez. 1964 .

8. BARBOSA, William et alii. Forma linfática - abdominal da blastomicose sul-americana. Revista do Instituto de Medicina Tropical, São Paulo, 10(1):16-27, jan./fev. 1968.

9. BARRos, Jaime Monteiro et alii. Blastomicose sul-americana. Boletim da Faculdade de Odontologia de Ribeirão Prêto, 1(3) :201-15, dez. 1964.

10. BELL, E. A textbook of pathology. 8.ed. Philadelphia, Lea \& Febiger, 1956. p. 251.

11. BELLIZZI, A. M. Manifestações bucais da blastomicose. Revista Brasileira de Odontologia, Rio de Janeiro, 17:155-9, mai./jun. 1959.

12. BERNIER, Joseph $\mathrm{L}$. The management of oral disease: a treatise on the recognition identification and treatment of diseases of the oral regions. 2. ed. St. Louis, Mosby, 1959. p. 351. 
13. BERNIER, Joseph Tratamiento de las enfermedades orales: um tratado sobre reconocimiento, identificación y tratamiento de las enfermedades de la region aral, Buenos Aires, Omeba, 1962. p.355.

14. BeviluaduA, S. Blastomicose da mucosa oral. Anais da Faculdade Nacional de Odontologia, Rio de Janeiro, 9:47-53, 1956.

15. BHASKAR, S. Synopsis of oral pathology. 2.ed. St. Louis, Mosby, 1965. p.497-9.

16. BOYD, William. Tratado de patologia general y anatomia patológica: una introducción a la medicina. Buenos Aires, Bernardes, 1952. p.251-491. ,

17. BOPP, C. Algumas considerações sôbre a micose de Lutz no Rio Grande do Sul. Anais da Faculdade de Medicina, Pôrto Alegre, 15:97-123, 1955.

18. BUCHMAN, Robert E. Bacteriology. 5.ed. New York, Macmillan, 1951. p.617-9.

19. BURKET, Lestes W. Medicina bucal; diagnóstico y tratamiento. México, Interamericana, 1954. p.405-6.

20. BURrows, W. Tratado de microbiologia. 18.ed. México, Interamericana, 1954. p.65-691.

21. CALmetTe, A. Manuel technique de microbiologie et sérologie. 4.ed. Paris, Masson, 1948. p.557.

22. CAMpos, J. A. Resumo estatístico dos casos de blastomicose bucofaringea observados no Serviço de Otorrinolaringologia da Santa Casa de São Paulo, nos anos de 1939 a 1944. 'In: II ${ }^{\alpha}$ Reunião anual dos dermato-silógrafos brasileiros. Minas Gerais, Imprensa Oficial, 1948. p.177-83.

23. CARTER, Charles F. Microbiology and pathology. St. Louis, Mosby, 1953. p.441.

24. CISALPINO, E. O. et alii. Experiência com um antígeno metílico para o diagnóstico da Blastomicose Sul-Americana. Arquivos do Centro de Estudos da Faculdade de Odontologia da Universidade de Minas Gerais. Minas Gerais, 1(1):117-21, jul./dez. 1964.

25. CONANT, Norman F. Manual of clinieal mycology. 2.ed. Philadelphia, W. B. Saunders, 1958. p75-92.

26. DEVILDOS, L. R. et alii. Blastomicose sul-americana: apresentação dos casos. Arquivo do Centro de Estudos da Faculdade de odontologia de Pelotas. 4(2):57-64, 1967.

27. EBLING, Hardy \& LOURO, L. Blastomicose sul-americana. Revista da Faculdade de Odontologia, Pôrto Alegre, 7:35-8, 1965.

28. EDWARD, A. Joseph et alii. Oral South American Blastomycosis in the United States. Oral Surgery, Oral Medicine and Oral Pathology, St. Louis, 21:732-7. jan./jun. 1966.

29. FAVA NETTO, C. et alii. Ocorrência familiar da blastomicose sulamericana (a propósito de 14 casos). Revista do Instituto de Medicina Tropical, São Paulo, 7(6): 332-6, nov./dez. 1965. 
30. FONSECA, J'. B. Blastomicose sul-americana: estudo das lesões dentárias e paradentárias sob o ponto de vista clínico e histopatoló. gico, São Paulo, 1957. Tese.

31. KARLHANS, Salfeder et alii. Experimental cutaneous South American blastomycosis in Hamsters. Archives of Dermatology, Chicago, 97:69, jan. 1968.

32. LACAZ, C. S. Contribuição brasileira para o estudo da Blastomicose sul-americana; granulomatose paracoccidiódica 0 Hospital, Rio de Janeiro, 28:249-60, 1945 ,

33. LAUAND, F. Contribuição para o estudo da moriologia do Paracocidioides brasiliensis nos tecidos orais. Araraquara, Faculdade de Farmácia e Odontologia de Araraquara, 1964. Tese.

34. LAUAND, F. Dois casos de blastomicose brasileira. Revista Brasileira de Odontologia, Rio de Janeiro, 18:1-5, 1960.

35. LONDERO, A. T. Blastomicose sul-americana. Revista da Faculdade de Farmácia e Bioquímica de Santa Maria. Santa Maria, 12(3): 63-76, 1965.

36. LONDERO, A. J. \& FABRICIO, R. Genital localization of South American Blastomycosis, a new case. Lycopathologia e Mycologia Applicata, Haia, 30(3-4) : 253-6, 1966.

37. NOVA, Rafael da. A blastomicose brasileira no domínio da oto-rhinolaringologia. Annaes Paulistas de Medicina e Cirurgia, São Paulo, 41:461, 1941.

38. RABELLO, F. E. et alii. A micose de Lutz: seus caracteres biológicos e clínicos. II reunião anual dos dermato-sifilógrafos brasileiros, Imprensa Oficial, Minas Gerais, 1948. 77-96.

39. ROCHA, Geraldo et alii. Blastomicose sul-americana ganglionar primitiva com calcificações abdominais. 0 Hospital, Rio de Janeiro, 70(6): :1632-44, dez. 1966.

40. Ramos, C. B. Granulomatose paraccoccidiódica. Revista da Associação Médica Brasileira, Rio de Janeiro, 7:22-30, 1961.

41. SILVA, N. N. da \& CAMPOS, E. C. A blastomicose de Lutz no Rio Grande do Sul. II ${ }^{*}$ reunião anual dos demato-sifilógrafos brasileiros. Minas Gerais, Imprensa Oficial, 1948. p.103-15.

42. SHAFER, William. Patologia bucal. Buenos Aires, Mundi, 1961. p.252-3.

43. SMITH, Alice Lorraine. Microbiology and pathology. 8.ed. St. Louis, Mosby, 1964. p.305-6.

44. THOMA, Kurt H. Oral pathology. 5.ed. St. Louis, Mosby, 1960. p.1013.

45. TIECKE, Richard W. et alii. Fisiopatologia bucal. México, Interamericana, 1960. p.33.

46. ZINSSER, Hans. Tratado de bacteriologia. Rio de Janeiro, Instituto Nacional do Livro, 1947. p.700; 725; 786. 

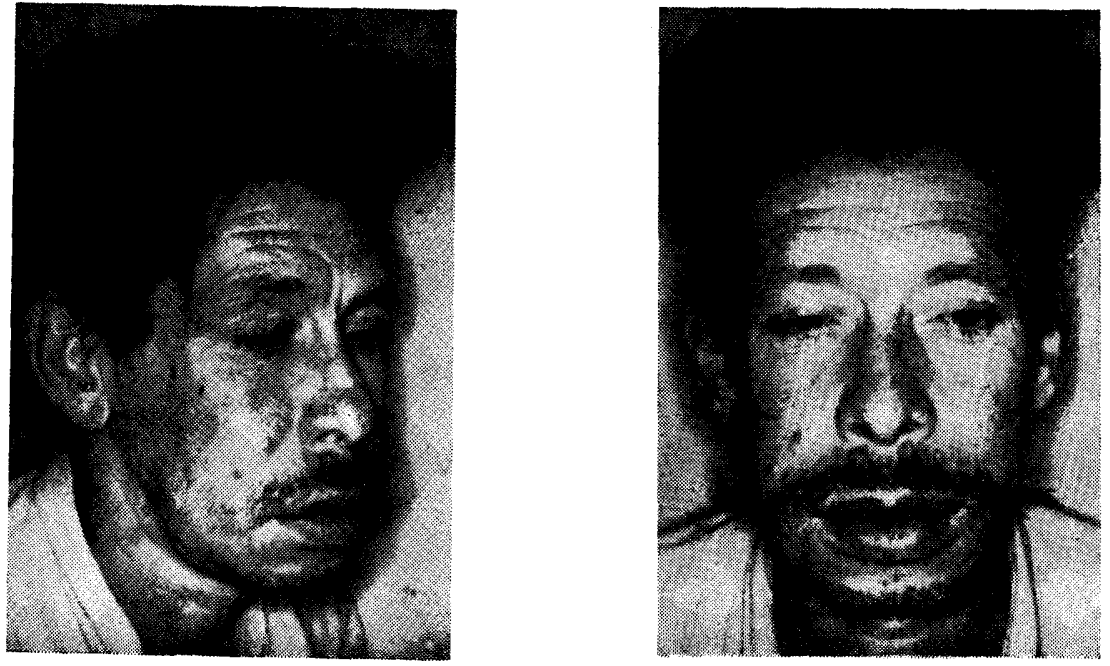

Fig. 1 e 2 - Aspecto facial de paciente com Blastomicose - Aspecto de «Lábio de Tapir».

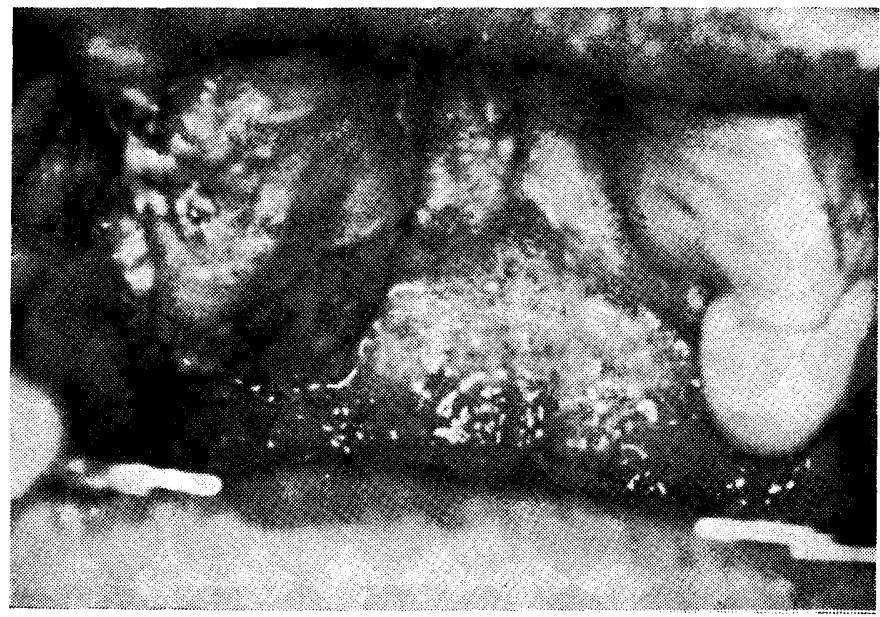

Fig. 3 - Fotografia intra-oral - aspecto «arenoso».

R! Fac. Odont. P. A.

$10 / 11: 145-159,1968 / 1969$ 


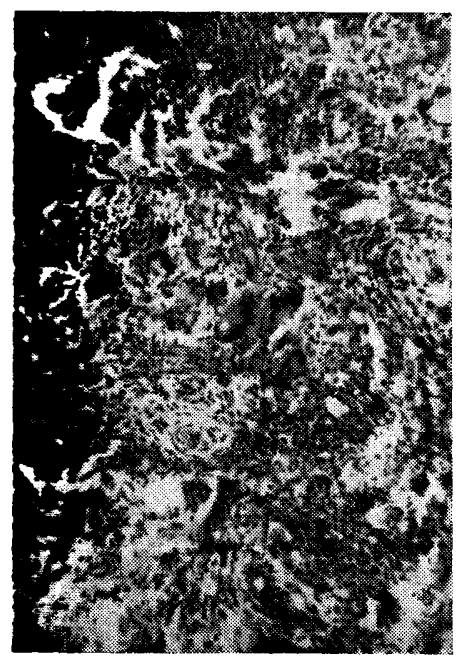

Fig. 4 - Micro-abcessos - são sugestivos, porém não característicos.

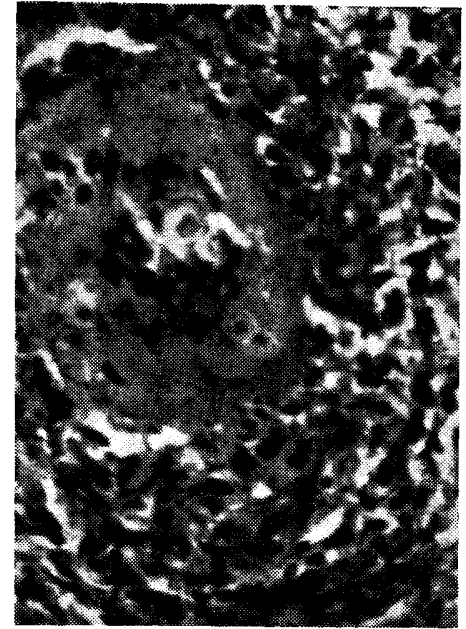

Fig. 5 - Células gigantes com parasitos em seu interior $(100 x)$

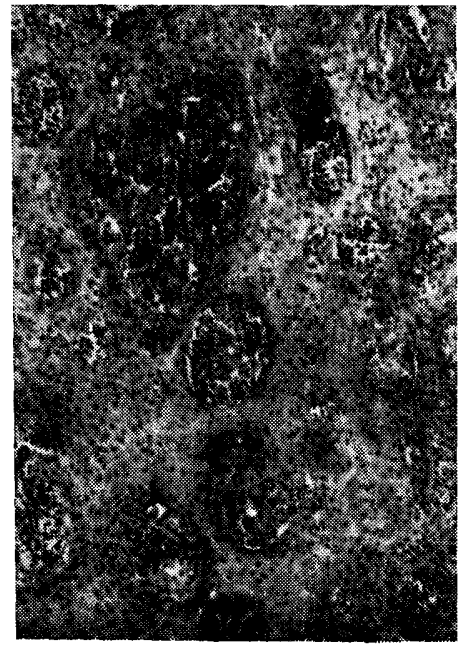

Fig. 6 - Celulas gigantes com vários microorganismos e $\mathrm{m}$ seu interior $(450 \mathrm{x})$

R. Fac. Odont. P. A. 